\title{
HUBUNGAN PANJANG STUMP TERHADAP TINGKAT KEMAMPUAN LOKOMOTOR PADA PASIEN PENGGUNA TRANSFEMORAL PROSTHESIS
}

\author{
Nur Rachmat, Muhammad Syaifudin, Putri Utami Sulistyawati
}

Politeknik Kesehatan Surakarta Jurusan Ortotik Prostetik

\begin{abstract}
Amputation, Stump Length, Locomotor Ability, Transfemoral Prosthesis. Transfemoral amputation is an amputation that removes part of the femur (Coletta, 2000) Classification of transfemoral amputation, short stump transfemoral is leaving less than $35 \%$ of the length of the femur. In the medium stump transfemoral leaving between 35\% - 60\% of the length of the femur. Long stump transfemoral remains among more than $60 \%$ of the length of the femur(Coletta, 2000). Loss of some lower extremity on the human body causes incapacity (disability) person to perform variety of activities (Bachtiar, 2014), and led to the disruption of the locomotor abilities and functional abilities of the body of the patient. (Raichle, 2008). Longer stump can improve locomotor abilities of the patient. The population in this study all patients adaah transfemoral amputation who came to Kuspito Clinic at Karanganyar, with total of 49 patients in 2015. Use of purposive sampling technique to obtained a sample of 30 patients with transfemoral prosthesis. Independent Variabel which is used in this research is the length of the stump, While Dependent Variable in this research is locomotor ability of transfemoral prosthesis patients. Hypothesis test results show the value of probability ( $p$-value) of $0.000<\alpha=0,05$ so that $\mathrm{HO}$ rejected and $\mathrm{H} 1$ accepted, which means there is a long-stump against the patient's level of ability of the locomotor pda transfemoral prosthesis users with value of correlation (r) 0.718 , the interpretation is strong correlation between variable.
\end{abstract}

Keywords: Amputation, Stump Length, Locomotor Ability, Transfemoral Prosthesis.

\begin{abstract}
Abstrak : Amputasi, Panjang Stump, Kemampuan Lokomotor, Transfemoral Prosthesis. Amputasi transfemoral adalah amputasi yang menghilangkan bagian dari tulang femur (Coletta, 2000) Klasifikasi pada amputasi transfemoral adalah short transfemoral menyisakan kurang dari $35 \%$ dari panjang tulang femur. Pada medium transfemoral menyisakan antara 35\% - $60 \%$ dari panjang tulang femur. Pada long transfemoral menyisakan antara lebih dari $60 \%$ dari panjang tulang femur. (Coletta, 2000) Hilangnya sebagian anggota gerak pada tubuh manusia menyebabkan ketidakmampuan (disability) seseorang untuk melakukan aktivitas yang bervariatif.(Bachtiar, 2014) dan menyebabkan terganggunya kemampuan lokomotor dan kemampuan fungsional tubuh pasien. (Raichle, 2008). Panjang stump dapat meningkatkan kemampuan lokomotor pasien.Populasi dalam penelitian ini adaah seluruh pasien amputasi transfemoral ang dating ke Klinik Kuspito Ortotik Postetik Jaten Karanganyar Solo Jawa Tegah berjumlah 49 pasien pada tahun 2015. Dengan teknik Purposive sampling diperoleh sampel sebanyak 30 pasien transfemoral prosthesis. Variabel bebas yang digunakan dalam penelitian ini adalah panjang stump. Sedangkan ariabel terikat dalam penelitian ini adalah kemampuan lokomotor pada
\end{abstract}


pasien pengguna transfemoral prosthesis. Hasil uji hipotesis menunjukan nilai probabilitas ( $p$-value) sebesar $0,000<\alpha=0,05$ sehingga $\mathrm{H} 0$ ditolak dan $\mathrm{H} 1$ diterima berarti ada hubungan panjang stump terhadap tingkat kemampuan lokomotor pda pasien pengguna transfemoral prosthesis dengan nilai korelasi (r) 0,718 yang berarti interpretasi kekuatan korelasi kuat.

Kata Kunci : Amputasi, Panjang Stump, Kemampuan Lokomotor, Transfemoral Prosthesis

\section{PENDAHULUAN}

Amputasi adalah tindakan pembedahan yang membuang sebagian tubuh. Tindakan amputasi dilakukan pada bagian kecil sampai bagian besar tubuh. (Thomas, 1993). Amputasi transfemoral adalah amputasi yang menghilangkan bagian dari tulang femur (Coletta, 2000).Kasus pada amputasi anggota gerak bawah, prevalensi di Amerika Serikat adalah $\quad 40 \%$ Transfemoral, $50 \%$ Transtibial, $10 \%$ Hip Disarticulation (Pitkin, 2011)Klasifikasi pada amputasi transfemoral adalah short transfemoral menyisakan kurang dari 35\% dari panjang tulang femur. Pada medium transfemoral menyisakan antara 35\% - $60 \%$ dari panjang tulang femur. Pada long transfemoral menyisakan antara lebih dari $60 \%$ dari panjang tulang femur. (Coletta, 2000)

Kemampuan lokomotor adalah kemampuan melakukan gerakan motorik anggota tubuh untuk memindahkan seluruh tubuh dari satu tempat ke tempat lain seperti berjalan, berlari dan melompat.Hilangnya sebagian anggota gerak pada tubuh manusia menyebabkan ketidakmampuan (disability) seseorang untuk melakukan aktivitas yang bervariatif.(Bachtiar, 2014) dan kehilangan anggota gerak bawah dapat menyebabkan terganggunya kemampuan lokomotor dan kemampuan fungsional tubuh pasien. (Raichle, 2008).
Ortotik Prostetik adalah pelayanan kesehatan yang di berikan oleh ortotis prostesis dalam hal alat bantu kesehatan berupa ortosis maupun prostesis untuk kesehatan fisik dan psikis berdasarkan ilmu pengetahuan dan teknologi untuk meningkatkan derajat kesehatan individu, kelompok dan masyarakat yang diakibatkan oleh adanya gangguan fungsi dan gerak anggota tubuh dan trunk (batang tubuh) serta hilangnya bagian anggota gerak tubuh yang dapat mengakibatkan gangguan atau kelainan anatomis, fisiologis, psikologis dan sosiologis.. Prostesis adalah alat pengganti anggota gerak tubuh yang dipasangkan di luar tubuh yang diperuntukkan bagi pasien/klien yang membutuhkan. (Permenkes, 2013)

Untuk membantu mengatasi keterbatasan-keterbatasan aktivitas yang terjadi pada seseorang yang kehilangan kaki akibat amputasi, digunakanlah prostesis.(Jumeno, 2007). Pada penangan transfemoral amputation, ortotik prostetik dapat memberikan pelayanan berupa prostesis yaitu transfemoral prosthesis, yang bertujuan untuk menggantikan anggota gerak bawah yang hilang. Dengan prostesis diharapkan anggota gerak penderita dapat dilengkapi sehingga ia dapat menjalankan aktivitasnya seharihari (Jumeno, 2007). Penggunaan prostesis dapat meningkatkan fungsional dan kualitas hidup pasien serta 
memungkinkan untuk kembali beraktivitas dan bekerja. (Raichle, 2008).

Untuk itu perlu penelitian untuk membuktikan bahwa semakin panjang stump sebagai variabel independen semakin baik kemampuan lokomotor pasien pengguna transfemoral prosthesis sebagai variabel dependen.

\section{METODE PENELITIAN}

Penelitian drencanakan di klinik Kuspito Ortotik Prostetik Jaten Karanganyar Surakata JawaTengah. Penelitian ini dilakukan pada bulan Januari 2016- Mei 2016. Jenis penelitian ini mengunakan metode cross sectional study dengan rancangan penelitian korelatif design, dimana dalam penelitian ini pasien telah megginakan transfemoral prostesis minimal 1 bulan da diukur panjang stump pasien serta di tes kemampuan lokomotornya. Populasi dalam penelitian ini adaah seluruh pasien amputasi transfemoral ang dating ke Klinik Kuspito Ortotik Postetik Jaten Karanganyar Solo Jawa Tegah berjumlah 49 pasien pada tahun 2015. Dengan teknik Purposive sampling diperoleh sampel sebanyak 30 pasien transfemoral prosthesis.

Variabel bebas yang digunakan dalam penelitian ini adalah panjang stump. Sedangkan variabel terikat dalam penelitian ini adalah kemampuan lokomotor pada pasien pengguna transfemoral prosthesis. Alat ukur yang digunakan untuk menentukan panjang stump adalah mid line. Sedangkan pada kemampuan lokomotor menggunakan indeks pengukuran berupa locomotor capabilities index $(L C I)$.

Untuk mengetahui hubungan panjang stump terhadap kemampuan lokomotor, menggunakan uji hipotesis berupa uji spearman untuk menentukan adakah hubungan dari variabel bebas dan terikat tersebut.

\section{HASIL PENELITIAN}

1. Karakteristik Responden

Karakteristik responden memuat data tentang latar belakang responden yang terdiri dari jenis kelamin, usia, jenis pekerjaan dan panjang stump. Deskripsi karakteristik responden adalah sebagai berikut.

\section{a. Karakteristik Jenis Kelamin}

\section{Tabel 1}

Distribusi Frekuensi Jenis Kelamin

\begin{tabular}{lll}
\hline Jenis Kelamin & N & $\%$ \\
\hline Laki - Laki & 21 & 70 \\
Perempuan & 9 & 30 \\
Jumlah & 30 & 100 \\
\hline
\end{tabular}

Hasil pengumpulan data pada tabel 1 menunjukan bahwa sebagian besar responden berjenis kelamin laki - laki yaitu sebanyak 21 orang $(70 \%)$

b. Karakteristik Usia

\section{Tabel 2}

Distribusi Frekuensi Usia

\begin{tabular}{lll}
\hline Usia & N & $\%$ \\
\hline $15-20$ & 5 & 17 \\
$21-26$ & 5 & 17 \\
$27-32$ & 1 & 3 \\
$33-38$ & 3 & 10 \\
$39-44$ & 8 & 27 \\
$45-50$ & 8 & 27 \\
Total & 30 & 100 \\
\hline
\end{tabular}

Hasil pengumpulan data pada tabel 2 menunjukan bahwa sebagian besar responden berusia 39 - 50 tahun yaitu sebanyak 16 orang (54\%) 
c. Karakteristik pekerjaan

Tabel 3

Distribusi Frekuensi Pekerjaan

\begin{tabular}{lll}
\hline Pekerjaan & N & $\%$ \\
\hline Kursus & 9 & 30 \\
Atlit & 1 & 3 \\
Swasta & 10 & 33 \\
Tukang Jahit & 5 & 17 \\
Ibu Rumah Tangga & 3 & 10 \\
Pegawai Kantor & 2 & 7 \\
Total & 30 & 100 \\
\hline
\end{tabular}

Hasil pengumpulan data pada tabel 3 menunjukan bahwa sebagian besar responden pekerja swasta yaitu sebanyak 10 orang $(33 \%)$

\section{Karakteristik Variabel}

Hasil pengukuran variabel penelitian yang terdiri dari panjang stump $(\mathrm{X})$ dan kemampuan lokomotor (Y) diperoleh hasil sebagai berikut:

a. Karakteristik Panjang stump

\section{Tabel 4}

Distribusi Frekuensi Panjang Stump

\begin{tabular}{lcc}
\hline Panjang Stump & $\mathrm{N}$ & $\%$ \\
\hline Short Stump & 10 & 33,3 \\
Medium Stump & 10 & 33,3 \\
Long Stump & 10 & 33,3 \\
Jumlah & 30 & 100 \\
\hline \multicolumn{1}{c}{ Berdasarkan } & hasil & penelitian
\end{tabular}

Berdasarkan hasil penelitian menunjukan bahwa distribusi panjang stump berdistribusi rata yaitu 10 orang $(33,3 \%)$

b. Karakteristik kemampuan lokomotor

Tabel 5

Distribusi Frekuensi Kemampuan Lokomotor

\begin{tabular}{lll}
\hline $\begin{array}{l}\text { Kemampuan } \\
\text { Lokomotor }\end{array}$ & $\mathrm{N}$ & $\%$ \\
\hline Sedang & 8 & 27 \\
Baik & 6 & 20 \\
Sangat Baik & 16 & 53 \\
Jumlah & 15 & 100 \\
\hline
\end{tabular}

Berdasarkan hasil penelitian menunjukan bahwa sebagian besar responden mempunyai kemampuan lokomotor sangat baik yaitu 16 orang $(53 \%)$

Berdasarkan hasil analisis uji rank spearman diketahui bahwa nilai probabilitas ( $p$-value) sebesar $0,000<\alpha=$ 0,05 sehingga $\mathrm{H} 0$ ditolak dan $\mathrm{H} 1$ diterima berarti ada hubungan panjang stump terhadap tingkat kemampuan lokomotor pda pasien pengguna transfemoral prosthesis dengan nilai korelasi (r) 0,718 yang berarti interpretasi kekuatan korelasi kuat.

\section{PEMBAHASAN}

Unsur-unsur yang terkandung dalam kemampuan motorik menurut Muthohir (2004) antara lain adalah kekuatan, koordinasi, kecepatan, keseimbangan, dan kelincahan. Dilihat dari para ahli, menunjukkan bahwa hasil penelitian ini mendukung pnelitian terdahulu dari Clark(2002) bahwa semakin tinggi level amputasi maka tingkat kestabilan pengguna semakin buruk. Vitriana (2002), dalam penelitiannya menunjukan bahwa level amputasi dimana 20\% - 50\% tulang tibia masih dapat mempunyai kestabilan atau keseimbangan optimal. Yi,et al(2009), mengungkapkan bahwa semakin dekat bidang tumpu dengan pusat gravitasi (semakin panjang ukuran puntung), maka stabilitas atau keseimbangan tubuh makin tinggi. Hilangnya anggota gerak bawah mengkibatkan terganggunya fungsi ekstremitas, dengan salah satunya adalah fungsi keseimbangan. Panjang puntung (stump) termasuk dalam kriteria yang panjang mampu untuk berjalan dengan baik (Thomson, 2001) 


\section{KESIMPULAN DAN SARAN}

Ada hubungan panjang stump terhadap tingkat kemampuan lokomotor pda pasien pengguna transfemoral prosthesis dengan nilai korelasi (r) 0,718 yang berarti interpretasi kekuatan korelasi kuat. Pada penelitian ini menyatakan bahwa semakin panjang stump maka kemampuan lokomotor pada pasien transfemoral prosthesis akan semakin baik. Saran untuk penelitian ini adalah agar peneliti atau praktisi Ortotis Prostetis yang akan datang, penelitian ini masih memiliki banyak keterbatasan, seperti faktor usia, jenis kelamin, kepercayaan diri, kekuatan otot, lama pemakaian. Diharapkan dalam penelitian selanjutnya, peneliti dapat menggunakan beberapa faktor tersebut sebagai variabel dalam hubungan terhadap kemampuan lokomotor.

\section{DAFTAR RUJUKAN}

C. L. Thomas (ed.) (1993), Taber's Cyclopedic Medical Dictionary, 17 ed, F. A. Davis, Philadelphia.

Clark, L. A. ; 2002 ; Balance in lower limb child amputees; Biomechanics Laboratory Department of Kinesiology, University of California ; Los Angeles.

Coletta EM. Care of the elderly patient with lower extremity amputation. J Am Board Fam Pract. 2000;13(1):23-34.

Dody Bactiar, Audy, Jamari, Iwan Budiwan. Perancangan Biomekanisme Sendi Prostesa Untuk Pasien Amputasi Tungkai Atas Lutut dengan Desain Ergonomi dan Fleksibel. Prosiding SNST ke-5 Tahun 2014
Jumeno, D., \& Isa, S. T. (2007). Tangan buatan berteknologi robot untuk penyandang cacat: Prosiding seminar nasional ergonomi dan K3. Semarang.

Pitkin, Mark R. 2011. Biomechanics for life: Introduction of sanomechanics. Springer science $\&$ business media

Thomsom, Ann., O’Sullivan ; 2001 ; Physical Balance ; Colonial Court Records ; Virginia

Vitriana., 2002; rehabilitasi pasien amputasi bawah lutut dengan menggunakan immediate post operative prosthetic; 